\author{
О.О. Журавльов, С.В. Орлов, Н.В. Шигімага
}

Харківський національний університет Повітряних Сил ім. І. Кожедуба, Харків

\title{
МЕТОД РОЗРАХУНКІВ ЗНАЧЕНЬ ГЕОДЕЗИЧНОЇ ДАЛЬНОСТІ, АЗИМУТА I ВИСОТИ ТОЧКИ В ЗАДАЧАХ ЗОВНІШНЬОЇ БАЛІСТИКИ
}

У статті розглянуто метод розрахунку значень геодезичної дальності (по поверхні земного еліпсоїда), азимута і висоти точки, координати якої задані в стартовій системі координат (ССК) при виріменні завдань зовнішньої балістики. Початок ССК визначено в геодезичній системі координат геодезичною широтою, довготою і висотою. Розв'язана задача перетворення значень координат точки з ССК в геодезичну систему координат (ГСК) шляхом проведення послідовних перетворень з ССК в прямокутну геоцентричну систему координат (ПГЦ СК), а потім з ПГЦ СК в ГСК. Особливістю перетворення координат з ССК в ПГЦ СК є додатковий облік складових повного ухилення прямовисній лінії в точиі початку ССК. Представлений вивід матрииі перетворення координат із ССК в ПГЦ СК. Проведено аналіз впливу неврахування ухилення прямовисній лінії в точизі початку ССК на точність обчислень значень геодезичної дальності, азимута і висоти точки. Представлені графіки залежності відносних похибок обчислення значень зазначених величин від величини повного ухилення прямовисній лінії в точџฺі початку ССК. Представлені оцінки абсолютних похибок. Зроблено висновок про необхідність додаткового обліку складових повного ухилення прямовисній лінії в точці початку ССК при проведенні точних обчислень значень геодезичної дальності, азимута і висоти точки, координати якої задані в ССК.

Ключові слова: стартова система координат, геодезична система координат, ухилення прямовисній лінії, перетворення координат, геодезична дальність, азимут, висота.

\section{Вступ}

Постановка проблеми. При точному вирішенні завдань експериментальної зовнішньої балістики і балістичного забезпечення стрільб виникає необхідність обчислювати значення геодезичної дальності $D$, азимута $A$ і висоти $h$ точки.

Для балістичних задач, в яких припустимо застосовувати в якості моделі Землі площину або сфеpy, величини $D, A, h$ легко знаходяться на основі геометрії та сферичної геометрії.

Точне рішення зазначених завдань зовнішньої балістики вимагає використовувати в якості моделі Землі земний еліпсоїд (наприклад, Красовського). У вищій геодезії розроблені алгоритми розрахунку значень геодезичної дальності $D$ і азимута $A$ між двома точками на поверхні земного еліпсоїда в геодезичній системі координат (ГСК), заданої геодезичної широти $\phi$, довготою $\lambda$ і висотою $h$ над поверхнею еліпсоїда.

Складність вирішення завдання обумовлена необхідністю послідовних перетворень значень координат точок з однієї системи координат (СК) в іншу. Тому виникає задача перетворення координат точок з ССК в ГСК.

Аналіз останніх досліджень і публікацій. У широко відомих роботах [1-4] розглянуті основні принципи та методи розробки математичних моделей руху балістичних об'єктів. Однак, методи розрахунку значень геодезичної дальності, азимута і висоти точки для еліптичної моделі Землі опущені. В роботі [1] представлений підхід для обчислення значень сферичної широти і довготи точки на основі інтегрування диференціальних рівнянь, які описують зміну цих величин.

У роботах [5-9] поставлене запитання не розглядалось. В роботі [10] представлена матриця перетворення координат точки з ССК в ПГЦ СК, однак, в ній не враховано повне ухилення прямовисній лінії в точці старту об'єкта.

У вищій геодезії [12] розроблені та описані методи перетворення координат точки з ПГЦ СК в ГСК і зворотне перетворення - з ГСК в ПГЦ СК.

Однак, перетворення координат точки з ССК в ГСК в доступній літературі по зовнішній балістиці не наводиться.

Метою статті $\epsilon$ розгляд методу розрахунків значень геодезичної дальності, азимуту и висоти точки при точному вирішенні задач зовнішньої балістики.

\section{Виклад основного матеріалу}

Для знаходження значень геодезичної дальності $D$, азимута $A$ і висоти $h$ точки, заданої координа- 
тами в ССК, потрібно провести послідовне перетворення координат з ССК в ПГЦ СК і з ПГЦ СК в ГСК. А потім, за знайденими геодезичними координатами $\phi, \lambda, h$ обчислюються значення $D, A$ та $h$.

За визначенням ССК $[1-4 ; 11]$ відомо, що її вісь спрямована вертикально вгору. По-цьому вона не збігається з нормаллю до поверхні земного еліпсоїда в цій точці (рис. 1). Цей не збіг осей характеризують повним ухиленням прямовисній лінії.

Ухилення прямовисних ліній необхідно знати для встановлення зв'язків між ГСК і ПГЦ СК, а також для математично строгого рішення різноманітних завдань на поверхні еліпсоїда і в просторі.

Розглянемо отримання матриці М перетворень значень координат із ССК в ПГЦ СК з урахуванням складових $\xi$, $\eta$ повного ухилення прямовисній лінії $u$, по якій направлена вісь ССК, від нормалі до поверхні земного еліпсоїда. Для цього потрібно провести 5 поворотів проти годинникової стрілки вихідної ССК в послідовності: $A_{c}->\eta_{c}->\phi_{c}^{1}->\lambda_{c}^{1}->\Lambda$, (може бути й інша послідовність поворотів, від якої буде залежати матриця $M$ ).

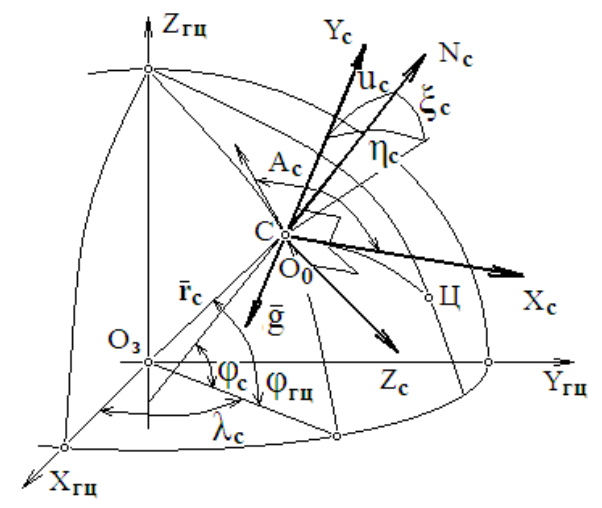

Рис. 1. Взаємозв'язок стартової, прямокутної геоцентричної і геодезичної систем координат Джерело: розроблено авторами.

Складемо елементарні матриці послідовних поворотів проти годинникової стрілки на один кут i перемножимо їх.

1. Проведемо поворот ССК $O_{0} X_{c} Y_{c} Z_{c}$ відносно вісі $O_{0} Y_{c}$ на кут $A_{c}$. При цьому повороті отримаємо систему $O_{0} X_{1} Y_{1} Z_{1}$ у якій вісь $O_{0} X_{1}$ лежить у площині місцевого меридіану та направлена в сторону півночі. Отримаємо першу одиничну матрицю перетворення $M_{A}$ :

$$
M_{A}=\left|\begin{array}{ccc}
\cos A_{c} & 0 & -\sin A_{c} \\
0 & 1 & 0 \\
\sin A_{c} & 0 & \cos A_{c}
\end{array}\right| .
$$

2. Проведемо поворот системи $O_{0} X_{1} Y_{1} Z_{1}$ відносно вісі $O_{0} X_{1}$ на кут $\eta_{c}$. Отримаємо систему
$O_{0} X_{2} Y_{2} Z_{2}$ у якій площина $O_{0} X_{2} Y_{2}$ розташована у площині місцевого меридіану. Отримаємо другу одиничну матрицю перетворень $M_{\eta}$ :

$$
M_{\eta}=\left|\begin{array}{ccc}
1 & 0 & 0 \\
0 & \cos \eta_{c} & \sin \eta_{c} \\
0 & -\sin \eta_{c} & \cos \eta_{c}
\end{array}\right| .
$$

3. Проведемо поворот системи $O_{0} X_{2} Y_{2} Z_{2}$ відносно вісі $O_{0} Z_{2}$ на кут $\phi_{c}^{1}=\phi_{c}-\xi_{c}$. Отримаємо систему $O_{0} X_{3} Y_{3} Z_{3}$ у якій вісь $O_{0} Y_{3}$ перпендикулярна вісі $O_{3} Z_{\text {ги }}$ ПГЦ СК, а вісь $O_{0} X_{3}$ розташована у площині місцевого меридіану та зіспрямована з віссю $O_{3} Z_{\text {ги }}$ ПГЦ СК. Отримаємо третю одиничну матрицю перетворення $M_{\phi}$ :

$$
M_{\phi}=\left|\begin{array}{ccc}
\cos \phi_{c}^{\xi} & \sin \phi_{c}^{\xi} & 0 \\
-\sin \phi_{c}^{\xi} & \cos \phi_{c}^{\xi} & 0 \\
0 & 0 & 1
\end{array}\right| .
$$

4. Проведемо поворот системи $O_{0} X_{3} Y_{3} Z_{3}$ відносно вісі $O_{0} X_{3}$ на кут $\lambda_{c}^{1}=0,5 \pi-\lambda_{c}$. Отримаємо систему $O_{0} X_{4} Y_{4} Z_{4}$ в якій вісь $O_{0} Y_{4}$ зі спрямована вісі $O_{3} Y_{z \varkappa}$, ось $O_{0} X_{4}$ зіспрямована вісі $O_{3} Z_{z u}$, а вісь $O_{0} Z_{4}$ спрямована у протилежну сторону відносно вісі $O_{3} X_{2 u}$ ПГЦ СК. Отримаємо четверту одиничну матрицю перетворень $M_{\lambda}$ :

$$
M_{\lambda}=\left|\begin{array}{ccc}
1 & 0 & 0 \\
0 & \cos \lambda_{c}^{1} & \sin \lambda_{c}^{1} \\
0 & -\sin \lambda_{c}^{1} & \cos \lambda_{c}^{1}
\end{array}\right| .
$$

Враховуючи, що

$$
\begin{aligned}
& \cos \lambda_{c}^{1}=\cos \left(0,5 \pi-\lambda_{c}\right)=\sin \lambda_{c} ; \\
& \sin \lambda_{c}^{1}=\cos \left(0,5 \pi-\lambda_{c}\right)=\cos \lambda_{c},
\end{aligned}
$$

матриця $M_{\lambda}$ прийме вигляд:

$$
M_{\lambda}=\left|\begin{array}{ccc}
1 & 0 & 0 \\
0 & \sin \lambda_{c} & \cos \lambda_{c} \\
0 & -\cos \lambda_{c} & \sin \lambda_{c}
\end{array}\right| .
$$

5. Для суміщення направлення однойменних вісей систем координат проведемо поворот відносно вісі $O_{0} Y_{4}$ на кут $\Lambda$. Отримаємо систему, $O_{0} X_{5} Y_{5} Z_{5}$ в якій всі вісі зіспрямовані однойменним вісям $O_{3} X_{2 u} Y_{z u} Z_{z u}$ ПГЦ СК.

Отримаємо п’яту одиничну матрицю перетворень $M_{\Lambda}$ : 


$$
M_{\Lambda}=\left|\begin{array}{ccc}
\cos \Lambda & 0 & -\sin \Lambda \\
0 & 1 & 0 \\
\sin \Lambda & 0 & \cos \Lambda
\end{array}\right| .
$$

При $\Lambda=0,5 \pi$ матриця $M_{\Lambda}$ прийме вигляд:

$$
M_{\Lambda}=\left|\begin{array}{ccc}
0 & 0 & -1 \\
0 & 1 & 0 \\
1 & 0 & 0
\end{array}\right| .
$$

Результуюча матриця $M$ отримується після послідовного перемноження 5-ти одиничних матриць:

$$
M=M_{\Lambda}\left\{M_{\lambda}\left[M_{\phi}\left(M_{\eta} M_{A}\right)\right]\right\},
$$

де $M$ - матриця перетворення $3 \times 3$;

$m_{i j}, i=\overline{1,3}, j=\overline{1,3}$ - елементи матриці $M$;

$$
m_{11}=\left(\cos \phi_{c}^{1} \sin A_{c} \sin \eta_{c}-\sin \phi_{c}^{1} \cos A_{c}\right) \cos \lambda_{c}-
$$$$
-\sin \lambda_{c} \sin A_{c} \cos \eta_{c}
$$

$m_{12}=\cos \phi_{c}^{1} \cos \lambda_{c} \cos \eta_{c}+\sin \lambda_{c} \sin \eta_{c} ;$

$m_{13}=\left(\cos \phi_{c}^{1} \cos A_{c} \sin \eta_{c}+\sin \phi_{c}^{1} \sin A_{c}\right) \cos \lambda_{c}-$ $-\sin \lambda_{c} \cos A_{c} \cos \eta_{c}$

$m_{21}=\left(\cos \phi_{c}^{1} \sin A_{c} \sin \eta_{c}-\sin \phi_{c}^{1} \cos A_{c}\right) \sin \lambda_{c}+$ $+\cos \lambda_{c} \sin A_{c} \cos \eta_{c}$

$m_{22}=\cos \phi_{c}^{1} \sin \lambda_{c} \cos \eta_{c}-\cos \lambda_{c} \sin \eta_{c}$;

$m_{23}=\left(\cos \phi_{c}^{1} \cos A_{c} \sin \eta_{c}+\sin \phi_{c}^{1} \sin A_{c}\right) \sin \lambda_{c}+$ $+\cos \lambda_{c} \cos A_{c} \cos \eta_{c}$

$m_{31}=\sin \phi_{c}^{1} \sin A_{c} \sin \eta_{c}+\cos \phi_{c}^{1} \cos A_{c} ;$ $m_{32}=\sin \phi_{c}^{1} \cos \eta_{c} ;$

$m_{33}=\sin \phi_{c}^{1} \cos A_{c} \sin \eta_{c}-\cos \phi_{c}^{1} \sin A_{c}$;

$$
\phi_{c}^{1}=\phi_{c}-\xi_{c} .
$$

Значення координат $\bar{X}_{G S}=\left(x_{2 u}, y_{z u}, z_{\text {ги }}\right)^{T}$ точки в ПГЦ СК розраховується на основі перетворення значень $\bar{X}_{S}=\left(x_{c}, y_{c}, z_{c}\right)^{T}$ координат в ССК за формулою:

$$
\bar{X}_{G S}=\bar{X}_{G S 0}+M_{S}^{(G S)} \bar{X}_{S},
$$

де $\bar{X}_{G S 0}=\left(x_{z ц 0}, y_{z ц 0}, z_{\text {ги } 0}\right)^{T}-$ координати ТС;

$$
M_{S}^{(G S)} \text { - матриця перетворення } 3 \times 3 \text {; }
$$

$m_{i j}, i=\overline{1,3}, j=\overline{1,3}$ - елементи матриці.

Значення координат $\bar{X}_{G S 0}=\left(x_{z u 0}, y_{\text {ги } 0}, z_{\text {ги } 0}\right)^{T}$ початку ССК в ГСК розраховуються за формулами [12]:

$$
x_{2 u 0}=\left(N_{c}+h_{c}\right) \cos \phi_{c} \cos \lambda_{c}
$$

$$
\begin{gathered}
y_{\text {ги } 0}=\left(N_{c}+h_{c}\right) \cos \phi_{c} \sin \lambda_{c} ; \\
z_{\text {ги } 0}=\left(N_{c}\left[1-e^{2}\right]+h_{c}\right) \sin \phi_{c} ; \\
N_{c}=a\left(\sqrt{1-e^{2} \sin ^{2} \phi_{c}}\right)^{-1}, \\
a=6378245 \mathrm{~m}
\end{gathered}
$$

де $\phi_{c}, \lambda_{c}, h_{c}$ - геодезичні широта, довгота та висота початку ССК відповідно;

$N_{c}$ - радіус кривизни першого вертикалу в ТС;

$a$ - більша піввісь еліпсоїду Красовського.

У вищій геодезії розроблений алгоритм обчислення значень $\phi, \lambda, h$ геодезичної широти, довготи та висоти точки по іiі просторовим прямокутним координатам $x_{2 u}, y_{z u}, z_{\text {ги }}$ в ПГЦ СК [12].

Значення геодезичної довготи $\lambda_{n}$ точки на поверхні земного еліпсоїда обчислюється за формулою:

$$
\lambda_{n}=\operatorname{arctg}\left(y_{\text {гип }} x_{\text {ги! }}{ }^{-1}\right) \text {. }
$$

При $z_{\text {ги }}>5 \times 10^{-11}$ значенні геодезичної широти $\phi_{n}$ і висоти $h_{n}$ точки обчислюють методом послідовних приближень:

$$
\begin{gathered}
h_{n i}=z_{\text {ги } n}\left(\sin \phi_{n i-1}\right)^{-1}-N_{i}\left(1-e^{2}\right) ; \\
\phi_{n i}=\operatorname{arctg} \times \\
\times\left(( N _ { i } + h _ { n i } ) \operatorname { s i n } \phi _ { n i - 1 } \left[\sqrt{\left.\left.x_{\text {гц }{ }^{2}+y_{\text {гй } n}^{2}}\right]^{-1}\right),}\right.\right.
\end{gathered}
$$

де:

$$
\begin{gathered}
\phi_{n 0}=\operatorname{arctg}\left(z_{\text {ги } n}\left[\sqrt{x_{2 u n}{ }^{2}+y_{z \varkappa n}{ }^{2}}\left(1-e^{2}\right)\right]^{-1}\right) ; \\
N_{i}=a\left[\sqrt{1-e^{2} \sin \phi_{n i-1}}\right]^{-1} .
\end{gathered}
$$

Ітераційний процес припиняється при виконанні умов:

$$
\left|\phi_{n i}-\phi_{n i-1}\right|<5 \times 10^{-11} \text {. }
$$

При $z_{\text {ги } n}<5 \times 10^{-11} ; \phi_{n}=0$.

$$
h_{n}=\sqrt{x_{\text {zu } n}^{2}+y_{\text {zu } n}^{2}}-a \text {. }
$$

Значення геодезичної дальності $D_{n}$ (по поверхні еліпсоїда) і азимута $A_{n}$ напрямку на точку розраховуються по геодезичних координатах точок старту $\phi_{c}, \lambda_{c}, h_{c}$ та падіння $\phi_{n}, \lambda_{n}, h_{n}$ за формулами:

$$
\begin{gathered}
D_{n}=\sqrt{P^{2}+Q^{2}} ; \\
A_{n}=\operatorname{arctg}\left(P Q^{-1}\right)-0,5 \Delta A,
\end{gathered}
$$




$$
\begin{gathered}
P=\Delta \lambda \cos \phi_{m} N_{m}\left[1+\left(\Delta \phi^{2}-\Delta \lambda^{2} \sin ^{2} \phi_{m}\right) 24^{-1}\right] ; \\
Q=\Delta \phi M_{m}\left[1-\Delta \lambda^{2}\left(2+\sin ^{2} \phi_{m}\right) 24^{-1}\right] ; \\
\Delta A=\Delta \lambda \sin \phi_{m} \times \\
\times\left[1+\left(3 \Delta \phi^{2}+2 \Delta \lambda^{2} \cos ^{2} \phi_{m}\right) 24^{-1}\right] ; \\
\Delta \lambda=\lambda_{n}-\lambda_{c} ; \Delta \phi=\phi_{n}-\phi_{c} ; \phi_{M}=0,5\left(\phi_{n}+\phi_{c}\right) ; \\
N_{m}=a W_{m}^{-1}, M_{m}=N_{m}\left(1-e^{2}\right) W_{m}{ }^{-2} ; \\
W_{m}=\sqrt{1-e^{2} \sin ^{2} \phi_{m}} .
\end{gathered}
$$

Неврахування складових $\xi, \eta$ повного ухилення прямовисної лінії $u$ у точці старту при перетворенні координат з ССК в ГСК приводить до похибок обчислень значень $D_{n}, A_{n}$ i $h_{n}$.

Проведено дослідження впливу неврахування значень $\xi$, ๆ при перетворенні координат з ССК в ГСК на похибку обчислень значень $D_{n}, A_{n} \mathrm{i} h_{n}$. Для прикладу прийнята точка 3 геодезичними координатами $\phi_{c}=50^{0}, \lambda_{c}=45^{0}, h_{c}=0 \mu$ i $A_{c}=45^{0} . \mathrm{B}$ ССК задавалися координати другої точки $\left(x_{n}, 0,0\right)$, $x_{n} \in[20,120] \kappa м$. За формулами (17), (23), (24) проводився розрахунок значень $D_{n}, A_{n} \mathrm{i} h_{n}$, в функції кута $u \in[1,15]$ угл. сек. В якості показника використовувалися похибки $\delta D, \delta A, \delta h$, значення яких обчислюються за формулами:

$$
\begin{gathered}
\delta q=\left(\frac{F_{q}^{u}}{F_{q}^{0}}-1\right) \times 100 \% ; q:=\{D, A, h\} ; \\
F_{q}^{u}=F_{D}\left[\phi_{c}, \lambda_{c}, h_{c}, A_{c}, u, x_{n}, 0,0\right] ; \\
F_{q}^{0}=F_{D}\left[\phi_{c}, \lambda_{c}, h_{c}, A_{c}, 0, x_{n}, 0,0\right],
\end{gathered}
$$

де $F_{D}[\circ], F_{A}[\circ], F_{H}[\circ]-$ оператори розрахунку значень $D_{n}, A_{n}, h_{n}$ відповідно.

Результати представлені на рис. 2-4.

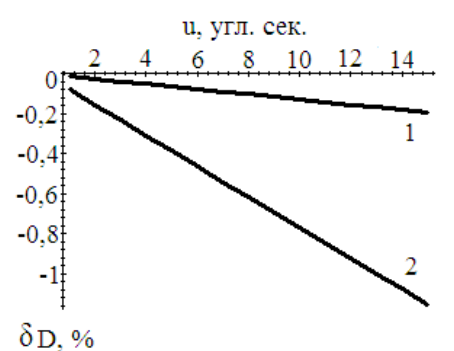

Рис. 2. Залежність відносної похибки $\delta D$ обчислення значень дальності від величини $u$ повного ухилення прямовисної лінії у точці старту: $1-D=120$ км; $2-D=20$ км

Джерело: розроблено авторами.

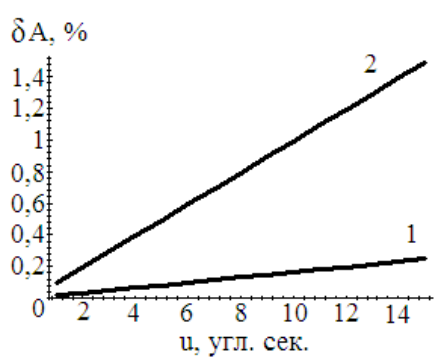

Рис. 3. Залежність відносної похибки $\delta A$ обчислення значень азимута від величини $u$ повного ухилення прямовисної лінії в точці старту: $1-D=120$ км; $2-D=20$ км Джерело: розроблено авторами.

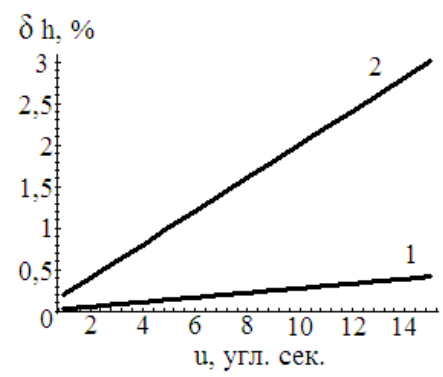

Рис. 4. Залежність відносної похибки $\delta$ обчислення значень висоти від величини $u$ повного ухилення прямовисної лінії в точці старту:

$1-D=120$ км; $2-D=20$ км

Джерело: розроблено авторами.

Абсолютні похибки обчислень значень дальності, азимута та висоти представлені в табл. 1.

Таблиця 1

Абсолютні похибки обчислень значень дальності, азимута та висоти

\begin{tabular}{|c|l|c|c|}
\hline \multirow{2}{*}{$\begin{array}{c}\text { Дальність, } \\
\text { км }\end{array}$} & Похибка & \multicolumn{2}{|c|}{$\begin{array}{r}\text { Повне ухилення } \\
\text { пряовисної лінії в } \\
\text { ТС, кут. сек. }\end{array}$} \\
\cline { 2 - 4 } & & \pm 1 & \pm 15 \\
\hline \multirow{3}{*}{20} & $\Delta D, \mathrm{M}$ & $\pm 15,4$ & $\pm 230,4$ \\
\cline { 2 - 4 } & $\Delta A$, угл. мін. & $\pm 2,7$ & $\pm 40,3$ \\
\cline { 2 - 4 } & $\Delta h, \mathrm{M}$ & $\pm 0,1$ & $\pm 1,4$ \\
\hline \multirow{3}{*}{120} & $\Delta D, \mathrm{M}$ & $\pm 15,5$ & $\pm 231,6$ \\
\cline { 2 - 4 } & $\Delta A$, угл. мін. & $\pm 0,4$ & $\pm 6,7$ \\
\cline { 2 - 4 } & $\Delta h, \mathrm{M}$ & $\pm 0,3$ & $\pm 5,1$ \\
\hline
\end{tabular}

У результаті проведеної оцінки встановлено, якщо не враховувати значень $u$ повного ухилення прямовисній лінії в точці початку ССК (яке може складати $3 \ldots 15$ кут. с.) при перетворенні значень координат точок з ССК в ГСК, то похибка обчислень значень буде складати:

$$
\Delta D- \pm(15,4 . .231,6) \mathrm{M} ;
$$




$$
\begin{gathered}
\Delta A- \pm(0,4 . .40,3) \text { кут. хв.; } \\
\Delta h- \pm(0,1 . .5,1) \text { м. }
\end{gathered}
$$

\section{Висновки}

В статті наведений метод розрахунків значень геодезичної дальності, азимуту і висоти точки при точному вирішенні задач зовнішньої балістики.
Для підвищення точності обчислень значень дальності, азимутів та висот точок, початкові координати яких задані в ССК, необхідно додатково враховувати відхилення вертикальної вісі ССК від нормалі до земного еліпсоїда в точці початку ССК, значення якого дорівнює значенню повного ухилення прямовисній лінії.

\section{Список літератури}

1. Дмитриевский А.А. Внешняя баллистика / А.А. Дмитриевский, Л.Н. Лысенко. - М.: Машиностроение, 2005. - 608 с.

2. Лысенко Л.Н. Внешняя баллистика / Л.Н. Лысенко. - М.: изд-во МГТУ им. Н.Э. Баумана, 2018. - 328 с.

3. Коновалов А.А. Внешняя баллистика / А.А. Коновалов, Ю.В. Николаев. - М.: ЦНИИ информации, 1979. -228 с.

4. Горовой С.А. Физические основы функционирования стрелково-пушечного артиллерийского и ракетного оружия. Баллистика / С.А. Горовой. - Новосибирск: СГГА, 2007. - 140 с.

5. Разработка подходов к решению обратной задачи внешней баллистики в различных условиях применения С.А. Королев, А.М. Липанов, И.Г. Русяк, В.А. Тененев // Вестник Томского государственного университета. - 2019. № 57. - С. 76-83.

6. Мельников П.Н. Моделирование траектории полета артиллерийского снаряда / П.Н. Мельников, А.А. Сазонов // Вестник Томского государственного университета. - 2018. - № 11. - С. 52-58.

7. Королев С.А. К вопросу о точности решения прямой задачи внешней баллистики / С.А. Королев, А.М. Липанов, И.Г. Русяк // Вестник Томского государственного университета. - 2017. - № 47. - С. 63-74.

8. Расчет траектории движения снаряда в атмосфере с учетом гидродинамики его обтекания / И.Г. Русяк, А.И. Карпов, С.А. Королев, С.А. Карсканов // Вопросы оборонной техники. - 2015. - № 2. - С. 130-141.

9. Метод расчета характеристик рассеивания неуправляемых вращающихся и оперенных реактивных снарядов / В.И. Макеев, В.И. Грабчак, П.Е. Трофименко, Ю.И. Пушкарёв // Системи обробки інформації. - 2009. - № 1(75). - С. 71-77.

10. Бельский А.Б. Теория и алгоритмы решения угломестных задач, определяющих положение летательного аппарата относительно цели [Електронний ресурс] / А.Б. Бельский, В.М. Чобан // Электронный журнал “Труды Московского авиационного института". - № 67. - С. 1-16. - Режим доступу: http://surl.li/ietl.

11. ГОСТ В 24288-80. Снаряды неуправляемые артиллерийские, реактивные, активно-реактивные. Методы расчета траекторий полета. - М.: Издательство стандартов, 1998. - 55 с.

12. Дементьев Ю.В. Алгоритмы и программы для вычислений в геодезии и гравиметрии: практикум / Ю.В. Дементьев, А.И. Каленицкий; под общ. ред. А.И. Каленицкого. - Новосибирск: СГГА, 2014. - 112 с.

\section{Відомості про авторів:}

Журавльов Олександр Олександрович кандидат технічних наук доцент провідний науковий співробітник Харківського національного університету Повітряних Сил ім. І. Кожедуба, Харків, Україна https://orcid.org/0000-0002-8176-3039

\section{Орлов Сергій Володимирович} кандидат технічних наук провідний науковий співробітник Харківського національного університету Повітряних Сил ім. І. Кожедуба, Харків, Україна https://orcid.org/0000-0003-3840-4089

\section{Шигімага Наталія Вікторівна} молодший науковий співробітник Харківського національного університету Повітряних Сил ім. І. Кожедуба, Харків, Україна https://orcid.org/0000-0002-6326-0008

\section{Information about the authors:}

\author{
Aleksandr Zhuravlev \\ Candidate of Technical Sciences Associate Professor \\ Lead Research \\ of Ivan Kozhedub Kharkiv \\ National Air Force University, \\ Kharkiv, Ukraine \\ https://orcid.org/0000-0002-8176-3039

\section{Sergei Orlov} \\ Candidate of Technical Sciences \\ Lead Research \\ of Ivan Kozhedub Kharkiv \\ National Air Force University, \\ Kharkiv, Ukraine \\ https://orcid.org/0000-0003-3840-4089
}

\author{
Natalia Shigimaga \\ Junior Research \\ of Ivan Kozhedub Kharkiv \\ National Air Force University, \\ Kharkiv, Ukraine \\ https://orcid.org/0000-0002-6326-0008
}




\title{
МЕТОД РАСЧЕТА ЗНАЧЕНИЙ ГЕОДЕЗИЧЕСКОЙ ДАЛЬНОСТИ, АЗИМУТА И ВЫСОТЫ ТОЧКИ В ЗАДАЧАХ ВНЕШНЕЙ БАЛЛИСТИКИ
}

\author{
А.А. Журавлев, С.В. Орлов, Н.В. Шигимага
}

В статье рассмотрен метод расчета значений геодезической дальности (по поверхности земного эллипсоида), азимута и высоты точки, координаты которой заданы в стартовой системе координат (ССК) при решении задач внешней баллистики. Начало ССК определено в геодезической системе координат геодезической широтой, долготой и высотой. Решена задача преобразования значений координат точки из ССК в геодезическую систему координат (ГСК) путем проведения последовательных преобразований из ССК в прямоугольную геочентрическую систему координат (ПГЦ СК), а затем из ПГЦ СК в ГСК. Особенностью преобразования координат из ССК в ПГЦ СК является дополнительный учет составляющих полного уклонения отвесной линии в точке начала ССК. Представлен вывод матрищь преобразования координат из ССК в ПГЦ СК. Проведен анализ влияния не учета уклонения отвесной линии в точке начала ССК на точность вычислений значений геодезической дальности, азимута и высоты точки. Представлены графики зависимости относительных погрешностей вычисления значений указанных величин от величины полного уклонения отвесной линии в точке начала ССК. Представлены оченки абсолютных погрешностей. Сделан вывод о необходимости дополнительного учета составляющих полного уклонения отвесной линии в точке начала ССК при проведении точных вычислений значений геодезической дальности, азимута и высоты точки, координаты которой заданы в ССК.

Ключевые слова: стартовая система координат, геодезическая система координат, уклонение отвесной линии, преобразование координат, геодезическая дальность, азимут, высота.

\section{METHOD OF CALCULATION OF GEODESIC RANGE, AZIMUTE AND POINT HEIGHT VALUES IN EXTERNAL BALLISTIC PROBLEMS}

A. Zhuravlev, S. Orlov, N. Shigimaga

In the article the geodetic ranges values calculating method (on the terrestrial ellipsoid surface) of point azimuth and height, coordinates of which are given in the start coordinate system when solving external ballistics problems is considered. In the known works the basic principles and methods of development of mathematical models of flight a projectile necessary for the decision of various ballistic problems are considered, a considerable quantity of works is devoted to development of mathematical models of flight a projectile in air of the Earth under various conditions. The center of the start coordinate system is defined in the geodetic coordinate system by the latitude, longitude and altitude. The problem of converting point coordinates from the start coordinate system to the geodetic coordinate system by performing successive transformations from the start coordinate system to a rectangular geocentric coordinate system and then from a rectangular geocentric coordinate system to a geodetic coordinate system is solved. A feature of the coordinates conversion from the start coordinate system to a rectangular geocentric coordinate system is the additional consideration of the vertical line complete deviation components at the start coordinate system start point. The derivation of the coordinate transformation matrix from the starting coordinate system to the rectangular geocentric coordinate system is presented. The analysis of the influence of not taking into account the deviation of the vertical line at the start coordinate system start point on the accuracy of the geodetic distance, azimuth and height of the point values calculations is performed. Graphs of calculation relative errors dependence of geodetic distance, azimuth and height of a point on size of full deviation of a vertical line at a point of the beginning of starting coordinate system are presented. Estimates of calculation absolute errors of geodetic range, azimuth and height of a point are presented. It is concluded that it is necessary to take into account the components of complete deviation of the vertical line at the start point of the start coordinate system when accurately calculating the values of geodetic range, azimuth and altitude of the point which coordinates are set in the start coordinate system.

Keywords: start coordinate system, rectangular geocentric coordinate system, geodetic coordinate system, vertical line deviation, coordinate transformation, geodetic range, azimuth, altitude. 